\title{
Crisis Pedagogy: Student Perceptions of Pedagogical Transition Amidst the COVID-19
}

\begin{abstract}
Rakesh Khanal ${ }^{1 *}$
${ }^{1}$ Asia Pacific International College, AUSTRALIA

*Corresponding Author: rakesh.khanal@apicollege.edu.au

Citation: Khanal, R. (2021). Crisis Pedagogy: Student Perceptions of Pedagogical Transition Amidst the COVID-19. Pedagogical Research, 6(2), em0094. https://doi.org/10.29333/pr/10826

ABSTRACT

The COVID-19 pandemic has affected every sphere of human life including education. Educational institutes all over the world are faced with the unique challenge to keep running the education amidst the lockdowns and social distancing. This has resulted in an unprecedented shift to the alternate mode of instructional delivery. This is a temporary shift in the mode of delivery as a result of the crisis or emergency situation. The present paper discussed the implications of one of such crisis pedagogies of remote learning during the COVID-19 propelled closure of the tertiary institutions in Australia. The effectiveness of emergency remote learning (ERL) was assessed through the online survey. The participants were international students, the majority, at the time of the survey were in Australia and doing postgraduate course in project management. To assess the overall effectiveness, the solicited opinions were analyzed under five headings: students' perception, curriculum, feedback, quality, and technology \& resource. The ERL model adopted in this study has two components: self-paced asynchronous learning and faculty-guided synchronous learning. The aim of the self-paced asynchronous learning was to provide the student access to learning and teaching materials which they could use safely, reliably and remotely, and later used those in their learning at their own pace. Similarly, the aim of the synchronous learning was to provide an interactive learning experience as in face-to-face teaching through faculty-guided live session. The result of the present study reveals that students perceived the ERL quite positively and are satisfied with the overall online learning and reported that transition to online learning from face-to-face was smooth and without much of the issue.
\end{abstract}

Keywords: emergency remote learning, COVID-19, pedagogy, online teaching, student perception, higher education

\section{INTRODUCTION}

The COVID-19 pandemic has created an unprecedented situation and as a result, every sphere of life is affected across the globe, including education. To contain the spread of the virus, Governments around the world took precautionary measures such as social distancing, drastic reduction in social, and economic activity and lockdowns. As a result of these measures and low economic activities, a 5.3\% contraction in the global gross domestic product is predicted for 2020 (World Bank, 2020). On the other hand, the closure of educational institutions has an unprecedented effect on learners. The UN Educational, Scientific, and Cultural Organization (UNESCO) data shows that $94 \%$ of the world's student population (about 1.6 billion) in more than 190 countries were affected by the closure of educational institutions at the peak of the crisis (UNESCO, 2020). UNESCO has predicted a 3.5\% decline in enrolment resulting in 7.9 million fewer students in tertiary education (UNESCO, 2020). This is going to have a huge impact on the national as well as the global economy. For instance, the higher education sector in Australia is one of the largest contributors to the national economy with an estimated contribution of around AUD 37.6 billion in the year 2018 (Tehan, 2019). The number of students enrolled in higher education, including vocational education and training (VET) in Australia is about 1.8 million (Bozkurt et al., 2020) of which 700,000 are the international students (Australian Trade and Investment Commiss \& Ion, n.d.). Australian Government data shows 9\% decline in international student's number in 2020 as compared to the similar period (JanuaryNovember) last year (Australian Trade and Investment Commission, n.d.). With the closure of the international border and subsequent decline in the number of international students, it was estimated that the university sector in Australia will have revenue fall in between AUD 3.1 billion to AUD 4.8 billion for the academic year 2020 and is projected to be around AUD 16 billion for 2020-2023 (Universities Autralia, 2020).

With new outbreaks, international border close, and lockdowns looming, the immediate future for the educational sector is uncertain. Under this condition of uncertainty to keep the education and business running, institutions all over the world are faced with the unique challenge to come up with the strategy that would make their teaching safe, stimulating, and engaging. Therefore, the educational sector (schools, colleges, and universities) around the world are reviewing, rethinking, and redesigning their 
pedagogical approaches. In this regard, many academics in various institutions around the world are compelled to take a breathtakingly fast transition from brick-and-mortar classroom to the virtual classroom to practice 'quarenteaching' (Pace, Pettit, \& Barker, 2020). Hodges et al. (2020) described this type of pedagogical transition to an alternate delivery mode, primarily online and remote, as a result of an emergency situation as the Emergency Remote Teaching (ERT). The same in this paper has been referred to as the Emergency Remote Learning (ERL).

It is noteworthy that the ERL is not the same as online learning, though the modality is virtual. The online learning is well researched and well-established pedagogy and literature are rich with volumes of work. Whereas, the ERL is a recent phenomenon which has emerged because of the COVID-19 pandemic and is a temporary shift in the mode of delivery. Once emergency situation is abated, it is expected that the mode of delivery will revert back to the original that would otherwise have been in a normal situation. Therefore, the ERL is primarily focused on ensuring the continuity of the educational process (teaching and learning) that has been disrupted by an adverse circumstance so that learners will have quick and reliable access to instruction and instructional support in a manner that is safe, reliable, and quick to setup. Also as opposed to online learning and distance education, which has always been an alternate and flexible means of learning, the ERL is an obligation (Bozkurt \& Sharma, 2020), hence priorities are different. When the ERL is understood in this context, the difference in pedagogical philosophies between the ERL and the other mode of learning, including online becomes clear that the primary objective is not to re-create a robust educational system but to provide quick, easy and reliable access to instruction and instructional support (Hodges et al., 2020). Many countries around the world have adopted this philosophy and continued their educational process amidst the COVID-19 pandemic using various means of remote learning such as radio learning, mobile learning, and internet learning to suit their contextual need.

In a recent study, Bozkurt et al. (2020) presented a global outlook to the interruption of education due to the COVID-19 pandemic reflecting on educational landscape from K12 to higher education from 31 countries across the globe and the educational practice adopted during the time of the crisis which they referred to as emergency remote education. Bozkurt et al. (2020) discussed about various issues such as physiological, technological and pedagogical resulting from the interruption of the education. To overcome pedagogical issues they emphasized on the importance of openness in education (Zawacki-Richter et al., 2020) and inclusion of alternate assessment and evaluation method. Similarly, Rahiem (2020) reported the ERL experience of the Indonesian university student from social science education program during the pandemic. The result of the study categorizes students' experience during ERL into two broad themes: blended learning and paradoxical learning. Blended learning includes elearning, $\mathrm{m}$-learning and conventional learning whereas paradoxical learning includes flexible learning from home and challenge imposed by remote learning. In another study, Mohmmed et.al. (2020) discussed the case of ERL implementation in the Middle East College in Oman. Their result shows students' apperception towards the effort of ERL implementation that allowed them to have uninterrupted teaching and learning during the pandemic. This study recommends the use of ERL as a means to support students' learning during the crisis time.

Against this background, this study is focused on assessing and understanding the effectiveness of the crisis pedagogy (refer to the section below) of remote learning adopted at the onset of the COVID-19 impelled closure of tertiary institutions in Australia. To the best of the author's knowledge work in this area in the Australian context is scarce in open literature, in particular, related to Australian non-university higher education provider is none. More importantly, as the ERL is a recent phenomenon little is known about the implementation of the crisis pedagogy of remote learning in higher education and how students perceived and experienced the situation compelled transition from face-to-face learning to remote learning. These are the impetus behind the present study which primarily explored students' perceptions of the ERL due to the COVID-19 crisis and also aimed at fulfilling the research gap on how to implement the ERL in a situation of the pandemic to meet learners' needs.

\section{PEDAGOGICAL APPROACH}

During the COVID-19 propelled lockdowns, educational institutions are doing whatever they could to keep their business and education running. This has unprecedently created a situation for remote learning, mostly internet based. In this regard, developed nations are at an advantage as they already have well-established infrastructure to support internet-based remote learning. To aid teachers in remote learning, a plethora of advice are coming from all corners of education, mostly from stakeholders from developed nations, with a focus on tools and materials that could be used to replace the face-to-face class. Much of this advice focuses on the tool-based pedagogy and teachers are using almost any available digital tools to ensure the continuation of teaching and learning. As these short-term temporary solutions are pedagogically, socially, politically, and economically necessary (Teräs et al., 2020) we should not be forgetful of the fact that tools are to facilitate the process of learning and not to replace it. Therefore, the researcher argues that the right approach of learning in this crisis period is process-based pedagogy with the emphasis on how learners will access the teaching and learning materials safely and reliably and use those in their learning with some sense of engagement as in face-to-face with friends and teachers.

The idea of instant dealing of the eminent threat resonates with the concept of crisis management where an organization focuses on a process to deal with the unexpected and disruptive events that challenge the very existence of a company and threats to harm the stakeholders. Like a company, educational institutions are also faced with the challenges that the COVID-19 has put forth by disrupting the conveyor belt of an educational process, and among their stakeholders, students are largely affected. Among various strategies of crisis management, process orientated crisis management is more applicable to deal with the present crisis. The process-oriented strategy is more focused on how crisis impacts an organization and the task needed to carry out to minimize the effect of the impact. By comparing a business organization with an educational institution one can recognize the present COVID-19 pandemic as a crisis event, disruption of the education as an impact of that event, and continuation of the 


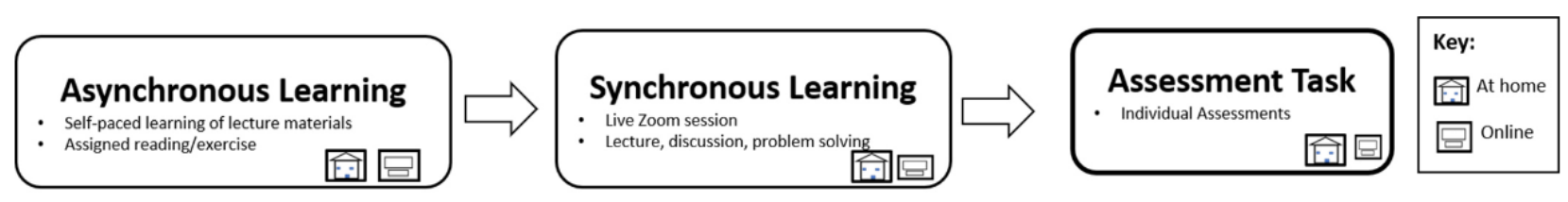

Figure 1. Model adopted for teaching postgraduate management course at the onset of the COVID-19 pandemic

Table 1. Comparison of the main features of teaching methods adopted after and before the COVID-19 Pandemic

\begin{tabular}{ccc}
\hline Features & Before COVID-19 Pandemic & After COVID-19 Pandemic \\
\hline Teaching methods & In-class, face-to-face and synchronous & Online, virtual, synchronous, and asynchronous \\
\hline $\begin{array}{c}\text { Learning Activities \& } \\
\text { Assessments }\end{array}$ & $\begin{array}{c}\text { Lectures, tutorials, assignments (group and } \\
\text { individual) and final exam }\end{array}$ & $\begin{array}{c}\text { Zoom lectures, online quizzes, tutorials, online assessments } \\
\text { (individual), online in-class activities, no final exam }\end{array}$ \\
\hline LMS & Canvas & Canvas \\
\hline
\end{tabular}

education as the task needed to minimize the impact. The right pedagogy ensures that task. In this study, the term crisis pedagogy is used to illustrate the emergency remote learning and teaching task that occurred to minimize the impact of the pandemic event while educational institutes are on forced shutdown and social distancing measures are in practice. Therefore, in the context of the present study, crisis pedagogy should be understood as crisis-aware teaching that involves design, develop, and delivery of teaching and learning activities and related assessments to better support students as they navigate through these uncertain times.

\section{Teaching Models}

Like thousands of teachers all over the world, the present author also faced the challenge of an unexpected and urgent request of shifting ongoing face-to-face class to be taught online and remotely from home as lockdowns and restriction began in New South Wales (NSW) Australia in March 2020. Before lockdowns, the present author was teaching postgraduate project management course in a face-to-face mode at Asia Pacific International College, a private non-university higher education institute in Sydney, Australia. With half of the course finished and delivered in face-to-face mode, shifting to the online within one week and completing the rest of the course teaching remotely was a unique challenge. The crisis pedagogy emerged as a plausible solution to deal with this unique challenge. The teaching model adopted to deal with this challenge is depicted in Figure 1, which consists of two basic components: self-paced asynchronous learning and faculty-guided synchronous learning.

The aim of the asynchronous learning was to provide all the learning and teaching materials such as power-point slides, companion readings, and some exercises to the students so that they could access all those learning materials remotely and safely from their home. Therefore, all teaching and learning materials were offloaded in the Learning Management System (LMS). The LMS used for this purpose was Canvas. It is well known that the LMS is key to administer web-based learning activities (El-Mowafy, Kuhn, \& Snow, 2013). The offloaded content in Canvas provided mobility to students' learning by enabling them to have safe and reliable access to learning resources at their own pace and comfort and with various devices (Canvas platform is compatible with many devices). The first purpose of the crisis pedagogy was thus achieved by allowing the student to have safe and reliable access to teaching and learning materials. Recently, a similar approach of teaching by combining an asynchronous and synchronous method was reported to be effective in content delivery, active learning, and student engagement during the COVID-19 pandemic (Sunasee, 2020). To give a broader perspective of the crisis model, Table 1 summarizes the comparison of its main features against the teaching model that was used to teach the author's course before the onset of the COVID-19 pandemic.

The second aim of the crisis pedagogy of engaging students in the learning process by establishing some sense of learner's community was achieved through Zoom-based live synchronous sessions which proved to be very useful in mimicking real-time face-to-face learning experience. Zoom-based synchronous lecture sessions were run every week for about two hours, with the focus of utilizing live-class time for meaningful learning and to encourage students to be more active participant which in turn will facilitate their needs for autonomy and competence as pointed out by self-determination theory (Cole, Feild, \& Harris, 2017). These live sessions were utilized not only to reinforce important concepts, but open discussions were also carried out on various aspects of students' learning during the crisis and encouraged the student to share their experience, how they were dealing with the crisis. Students were also encouraged to share and discuss issues and problems among themselves and in a group during the live sessions. Students were especially encouraged to turn their video on during the live session so that they have some sense of community and belonging. These are very essential, particularly, in this hard time as students do not have an opportunity to meet in person. On the other hand, it was observed that students were less keen to keep their video on while in a live Zoom lecture session. The possible reasons could be that the circumstances in which students were in synchronous learning were not so conducive because of the third-person presence in the home or feeling of not properly dressed for the live sessions or behavioral preference. Nonetheless, the students' engagement in the live session was good.

\section{Assessments}

It is noteworthy that in the abrupt emergency pivot to the remote learning, assessment should not be pushed aside as they are still an important part of the course learning outcomes, and instead some changes in the assessment regimes are required. According to the University of Illinois and Indiana University report (Jankowski, 2020), 97\% of the educational institute in the USA has made some changes in the assessment regime in response to the COVID-19 pandemic. Likewise, higher educational institutes in Australia also made some form of change in their assessment regime. The change that was made in the author's course in the 
Table 2. List of survey questions used in the research

\begin{tabular}{|c|c|}
\hline Question Number & Description \\
\hline Q1 & I am more engaged in my online learning \\
\hline Q2 & I have more opportunities to reflect on what I have learned in online unit \\
\hline Q3 & There are more opportunities to collaborate with other students in remote online learning \\
\hline Q4 & My online experience has increased my opportunity to access and use information \\
\hline Q5 & I am more likely to ask questions in an online learning \\
\hline Q6 & I can manage my own learning better in online learning \\
\hline Q7 & I am interested to take more online units \\
\hline Q8 & Response time from Lecturer is quicker in remote online learning \\
\hline Q9 & The workload demands for the unit were realistic for remote online learning \\
\hline Q10 & The content of the videos provided as part of learning was relevant to the learning outcomes of the course \\
\hline Q11 & The lecturer was supportive and responsive to my questions \\
\hline Q12 & My expectations for the units were met through remote online learning \\
\hline Q13 & Transition from face-to-face Teaching to remote online teaching was smooth without much of the issue \\
\hline Q14 & Online learning resources are made easily available through library service and in Canvas \\
\hline Q15 & The learning activities were relevant to Unit Learning Outcomes \\
\hline Q16 & Allocated lecture time of 2 hours were sufficient \\
\hline Q17 & I would prefer to have pre-recorded lecture videos \\
\hline Q18 & I came prepared for the class by going through the learning materials in advance \\
\hline Q19 & As in face-to -face teaching, I am aware of the importance of Academic Integrity in remote online learning environment \\
\hline Q20 & Overall, I am satisfied with remote online learning \\
\hline
\end{tabular}

assessment regime (also refer to Table $\mathbf{1}$ ) is in line with this global trend. As seen in Table 1, the tutorial sessions were still a part of the online sessions and were primarily used for assessment scaffolding and problem-solving. One of the major changes that were made in the assessment regime was the introduction of high-level thinking assessments instead of the end-of-semester final exam. The new assessment provided students an ample opportunity to demonstrate their learning through an alternate measure. As per the report of the National Institute of Learning Outcomes Assessment (Jankowski, 2020), alternate assessment is one of the five changes students like to see continued in the future after the COVID-19 crisis. Means and Neisler (2020) reported that students were more satisfied when they were asked to reflect on their own learning experience on what they have learned and what they need to learn. One of the alternate assessments that were introduced in the author's course was the reflection which was aligned with meaningful and authentical assessment practice.

\section{METHODOLOGY}

To understand students' perception of the ERL and to assess the effectiveness of crisis pedagogy, this study adopted quantitative data collection method (survey research). The study was conducted in the first trimester of the academic year 2020 in the post graduate level course in project management.

\section{Participants}

Eighty-one international students, who were taking project management subject (Project Risk, Quality and Procurement management) when the COVID-19 pandemic hit and had to finish the course by learning remotely responded to the survey questionnaire. It was assumed that each participant would be honest in recording their response and the participants were the representative of the learner's population who were taking the project management course remotely and online at post graduate level.

Students enrollment in the subject was quite diverse with majority from Asian country. About $83 \%$ of the students were from Asian country (South Asia, South-East Asia, and East Asia), 12\% from South America, 3\% from Africa, 1\% from North America and $1 \%$ from Transcontinental country. Of the enrolled students, $80 \%$ were male and $20 \%$ were female. These students had no prior experience of learning in an environment other than traditional (face-to-face). As a result, the present author felt more challenge in implementing ERL and assessing students' perception became more important.

\section{Instrument for Data Collection}

Data were collected through the convenience sampling using online-based questionnaire. Online-based questionnaire allowed the respondents to answer the questions anonymously without any social pressure thus minimizing the condition for social desirable bias (Pattanaphanchai, 2019). In addition, online survey allowed researcher the ease of access to the survey data due to the COVID-19 restrictions. While designing the online survey, guidelines as described in Andrews, Nonnecke and Preece (2003) were adopted. The survey consisted of twenty questions (refer to Table 2) designed to solicit students' opinions on the ERL using a five-point Likert scale from "Strongly Disagree" to "Strongly Agree". The items of the survey questionnaire were developed based on the previous work of Khanal (2020), Yan, Yan and Durrington (2010) and Eom and Ashill (2016). Survey questions were presented in a sequential form in a single screen. For each of the participant the order of the questionnaire was random. This was done to minimize the chances of response bias. 
Table 3. Descriptive statistics of survey items as per the identified Heading

\begin{tabular}{|c|c|c|c|}
\hline Heading (Overall mean) & Question & Mean & Std Dev \\
\hline \multirow{9}{*}{$\begin{array}{c}\text { Students' Perception } \\
\text { (3.6) }\end{array}$} & Q1 & 3.60 & 1.14 \\
\hline & Q2 & 3.57 & 1.14 \\
\hline & Q3 & 2.88 & 1.32 \\
\hline & Q4 & 3.79 & 1.02 \\
\hline & Q5 & 3.67 & 1.18 \\
\hline & Q6 & 3.65 & 1.17 \\
\hline & Q7 & 3.46 & 1.39 \\
\hline & Q18 & 3.62 & 0.97 \\
\hline & Q19 & 4.19 & 0.66 \\
\hline \multirow{5}{*}{$\begin{array}{c}\text { Curriculum } \\
(3.56)\end{array}$} & Q9 & 3.56 & 1.23 \\
\hline & Q10 & 4.06 & 0.73 \\
\hline & Q15 & 4.13 & 0.69 \\
\hline & Q16 & 3.88 & 0.99 \\
\hline & Q17 & 3.71 & 1.16 \\
\hline \multirow{2}{*}{ Feedback (4.03) } & Q8 & 3.81 & 0.97 \\
\hline & Q11 & 4.25 & 0.77 \\
\hline \multirow{2}{*}{$\begin{array}{c}\text { Quality } \\
\text { (3.5) }\end{array}$} & Q12 & 3.40 & 1.19 \\
\hline & Q20 & 3.63 & 1.24 \\
\hline \multirow{2}{*}{ Technology \& Resource (3.76) } & Q13 & 3.50 & 1.16 \\
\hline & Q14 & 4.02 & 0.83 \\
\hline
\end{tabular}

\section{Survey Administration}

The survey was administered online in Microsoft Teams platform and data were collected through convenience sampling during the final teaching week (week 10/11) between April 27 and May 15, 2020. The URL of the online survey was made available to all the participants through the Canvas course announcement which also stated the purpose of the survey, who was conducting it, the estimated time required to complete it and who to contact with questions. While administrating the survey ethical issues such as privacy and confidentiality and right to withdraw or omission of items was ensured through the proper setting of the online survey administration tool. It is noteworthy that though in the present study, survey questions were presented in a single screen in a sequential form, but for the country with slow internet connection if similar survey is to be carried out, it can be presented on a sequential screen. This method of survey design is especially useful to prevent the potential server time-outs for the respondents with slow internet connection and prevent the need for the participants to scroll through the pages (Schleyer \& Forrest, 2000).

\section{Data Analysis}

Survey data stored in Microsoft Teams database were imported into SPSS for statistical analysis. Microsoft Teams offers reliable and convenient data management and ensure the integrity of the collected survey data. In a recent study, suitability of the similar platform for online learning has been reported by Pal and Vanijja (2020). The reliability of the survey questionnaire in terms of internal consistency was tested using Cronbach's alpha. The calculated Cronbach's alpha value of 0.95 indicates a very good level of internal consistency of the survey questionnaire as the value of Cronbach's alpha of around 0.7 or greater is widely considered desirable (Taber, 2018). Since the focus of the present study was to understand students' perception on ERL as a result of abrupt disruption of education, the measure employed to analyze and describe the survey data was descriptive statistics. Similar approach of data analysis pertaining to the online study has been reported by Markova et al. (2017) and more recently by Naik et al. (2021) and Nam-Nguyen et al. (2020) in relation to the ERL. It is noteworthy that the descriptive approach in understanding a phenomenon is especially useful for situations where little is known (Morgan, 2015) and ERL is a recent phenomenon.

\section{RESULTS AND DISCUSSION}

The results were analyzed by grouping survey questions under five different headings. Each heading consisted of questions representing a particular aspect of the online remote learning. For the present research, these aspects are termed as areas. For example, Students' Perception is one of the five headings which consists of eight questions representing seven areas of the online learning such as self-engagement, student-student engagement, student-teacher engagement, time management, motivation, readiness, and academic integrity. Each of the heading is analyzed separately and students' opinion towards ERL is described in terms of these headings. Table 3 presents the descriptive statistics for the survey questionnaire as per the identified headings.

It is evident from Table 3 that the overall mean for each of the heading is higher than the mean opinion rating of 3 suggesting that students' overall opinion towards the ERL is positive. However, further analysis of the descriptive statistics for Q3 ("There are more opportunities ... in an online remote learning") revealed that though students positively perceived the ERL, their perception about online collaboration was not so positive. The mean value for Q3 is 2.88 (SD $=1.32$ ) which is $4 \%$ lower than the mean opinion rating of 3 and is the lowest among all means. From this comparison, it can be argued that Q3 had the least contribution in measuring students' perception. This result is further discussed in the section below. 


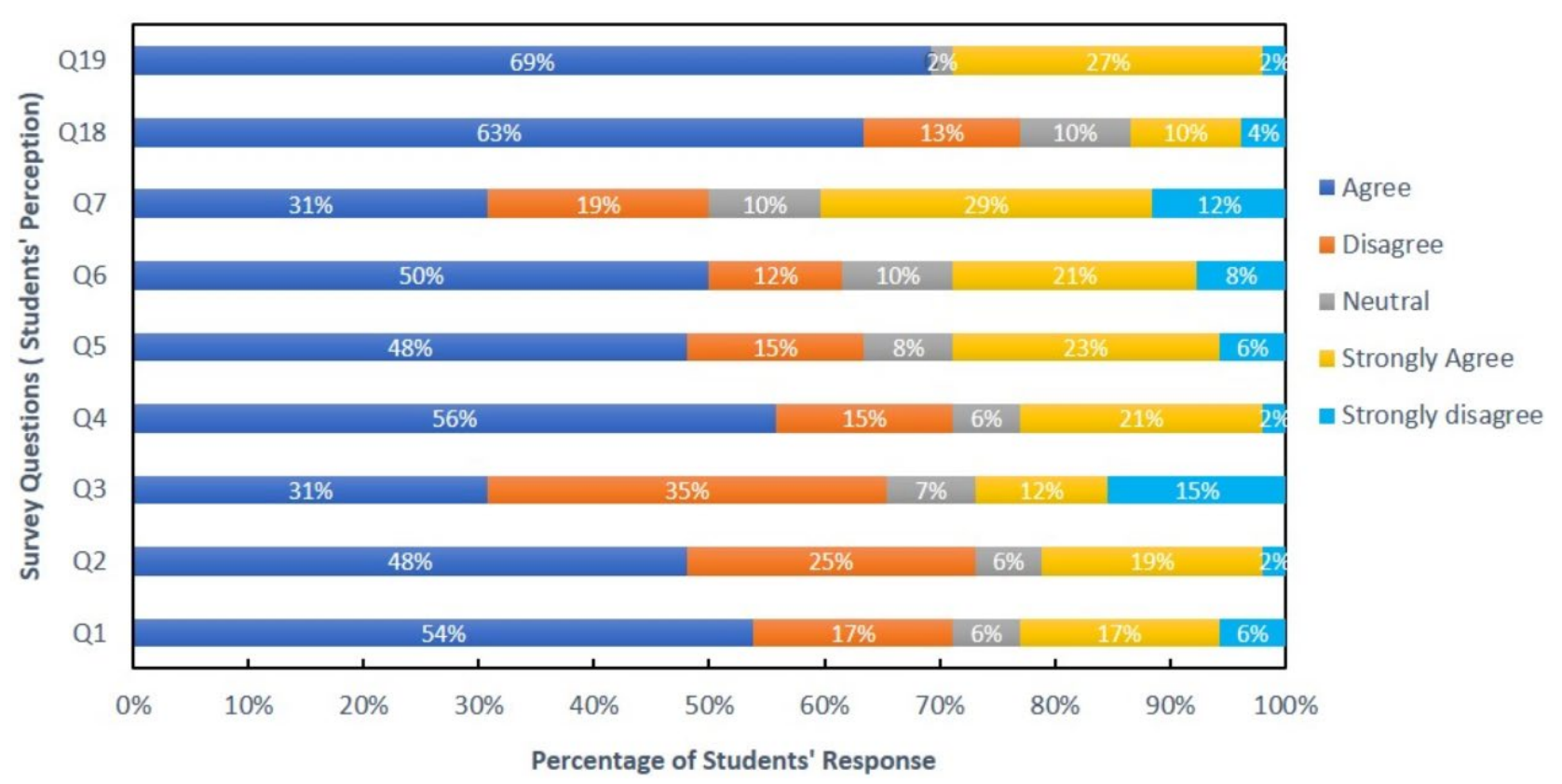

Figure 2. Survey result for the Heading-Students' Perception

Table 4. Descriptive Statistics for the Heading-Student's Perception

\begin{tabular}{|c|c|c|c|}
\hline Question Number & Description & Area & Mean (SD) \\
\hline Q1 & I am more engaged in my online learning & Self-engagement & \\
\hline Q2 & I have more opportunities to reflect on what I have learned in online units & Self-engagement & $3.6(11)$ \\
\hline Q4 & My online experience has increased my opportunity to access and use information & Self-engagement & \\
\hline Q3 & $\begin{array}{c}\text { There are more opportunities to collaborate with other students in remote online } \\
\text { learning }\end{array}$ & $\begin{array}{l}\text { Student-student } \\
\text { engagement }\end{array}$ & $2.88(1.32)$ \\
\hline Q5 & I am more likely to ask questions in an online learning. & $\begin{array}{l}\text { Student-teacher } \\
\text { engagement }\end{array}$ & $3.67(1.18)$ \\
\hline Q6 & I can manage my own learning better in online learning & Time management & $3.65(1.17)$ \\
\hline Q7 & I am interested to take more online units & Motivation & $3.46(1.39)$ \\
\hline Q18 & I came prepared for the class by going through the learning materials in advance & Readiness & $3.62(0.97)$ \\
\hline Q19 & $\begin{array}{l}\text { As in face-to-face teaching, I am aware of the importance of Academic Integrity in } \\
\text { remote online learning environment. }\end{array}$ & Academic Integrity & $4.16(0.66)$ \\
\hline
\end{tabular}

\section{Students' Perception}

The fundamental premise underpinning much of the modern educational thought lies on the fact that students attend educational institute, in a large part, is to gain opportunities to learn. Therefore, student's learning opportunities may be best described as individual perceptions (Dumas, 2018). For the present study, seven such perceptions have been broadly classified under the heading Students' Perception. The seven areas of students' perception identified in this study are self-engagement, student-student engagement, student-teacher engagement, time management, motivation, readiness, and academic integrity. $45 \%$ of the survey questions belongs to this heading making it the largest among all headings. Figure 2 presents the survey results for Students' Perception where the percentage of students' response rate for each of the heading's question is shown.

It is evident from Figure 2 that the overall Students' Perception regarding the ERL is quite positive with the response typically centered around "Agree" and "Strongly Agree". In overall, the average response rate of "Agree" and "Strongly Agree" for Students' Perception is $70 \%$. However, for an individual question the overall response rate of 'Agree" and 'Strongly Agree" varies from $42 \%$ (for Q3) to 96\% (for Q19). To further understand the specific nature of the response, questions were analyzed based on the areas. Table 4 presents area wise descriptive statistics for Students' Perception.

It is clear from Table 4 that except Q3 ("There are more opportunities...in remote online learning"), all other questions in the area have response rates centered around "Agree" and "Strongly Agree". Question 3 has the least contribution (mean = 2.88) among all the items of the heading in determining the overall students' perception regarding the ERL. It is conjectured that the negative rating towards the opportunity of online collaboration may have resulted from a change in the assessment regime. Before the COVID-19 pandemic, students had the opportunity to work in a group for an assignment which was $30 \%$ worth. Whereas, after the COVID-19 outbreaks, all the remaining assignments were converted into an individual task. The students might have perceived this as no opportunity to collaborate and would have affected their opinion about collaboration in an online environment. Nonetheless, this result has raised an important question that if ERL is to be made effective in the future as we do not know when this crisis is going to be over and normalcy will return, assessment design needs careful consideration with ample opportunity for 
Table 5. Descriptive Statistics for the Heading- Curriculum

\begin{tabular}{|c|c|c|c|}
\hline Question Number & Description & Area & Mean (SD) \\
\hline Q9 & The workload demands for the unit were realistic for remote online learning & Course design & \multirow{3}{*}{$3.86(0.97)$} \\
\hline Q15 & The learning activities were relevant to unit learning outcomes & Course design & \\
\hline Q16 & Allocated lecture time of 2 hours were sufficient. & Course design & \\
\hline Q10 & $\begin{array}{l}\text { The content of the videos provided as part of learning was relevant to the learning } \\
\text { outcomes of the course. }\end{array}$ & Course content & \multirow[t]{2}{*}{$3.89(0.94)$} \\
\hline Q17 & I prefer to have pre-recorded lecture videos. & Course content & \\
\hline
\end{tabular}

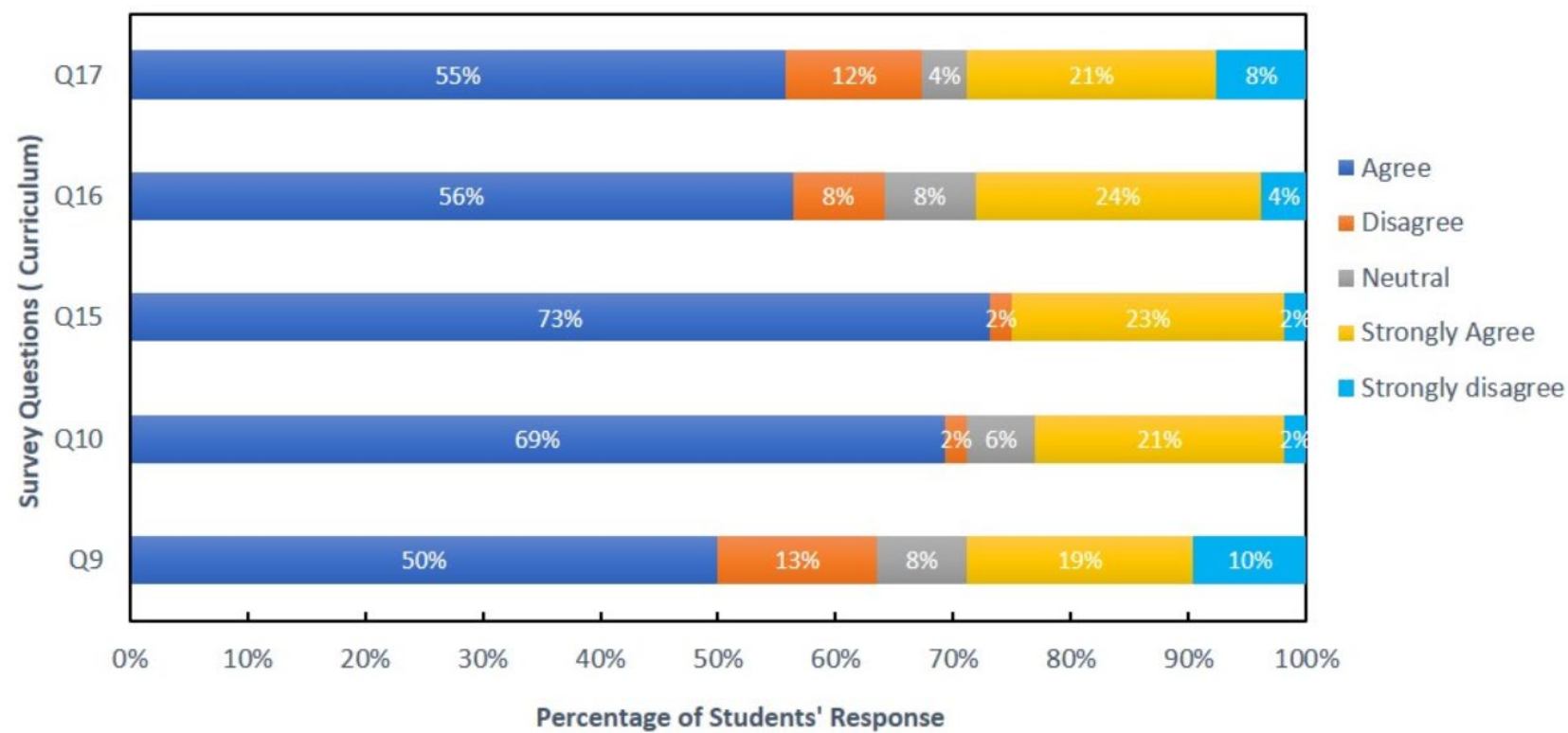

Figure 3. Survey result for the Heading-Curriculum

collaborative assignment work. Collaboration promotes active learning and enhances the students' motivation (Mora, SignesPont, Fuster-Guilló, \& Pertegal-Felices, 2020).

It is noteworthy that the students' response to the Question 19 ("As in face-to-face ... remote online learning environment") has the highest mean score of 4.16 with an average response rate of more than $90 \%$ (refer to Figure 2) centered around "Agree" and "Strongly Agree". This result suggests that students viewed Academic Integrity as equally important during the ERL as in normal condition when classes were running in face-to-face mode. This result is quite encouraging and suggests that students take academic integrity matter seriously as opposed to the general view that during the crisis time academic integrity will be overlooked as ERL is a recent phenomenon and has posed challenges across the universities in assessment design, in particular, safeguarding academic integrity (Gamage, de Silva, \& Gunawardhana, 2020). From the survey result it is clear that out of seven areas of students' perception, student perceived academic integrity with more value followed by student-teacher engagement, time management, self-engagement, motivation, readiness, and student-student engagement. In overall, results of Figure 2 and Table 4 suggest that during the ERL, students were motivated and engaged with the online learning; they were prepared and effectively managing their time and conducting their study with full awareness of academic integrity matters.

\section{Curriculum}

A curriculum defines the learning that is expected to take place during a course of study and encompasses teaching, learning and assessment methods, and indicates the learning resources required to support effective delivery (McKimm \& Barrow, 2009). In a broad sense, curriculum primarily encompasses course design and course content. Therefore, in the present study, Course Design and Course Content are considered as two areas of interest under the heading Curriculum. The Curriculum consists of five questions making it the second-largest contributor to the survey questionnaire with $15 \%$ questions from the course design area and $10 \%$ from the course content area. The descriptive statistics for Curriculum is presented in Table 5.

From Table 5, it is evident that the calculated value of mean for both the areas (course design and course content) are significantly higher than the mean rating of 3. Also, the calculated means are very close to one another. This result suggests that students are satisfied with the way the course was designed and delivered online during the COVID-19 pandemic. This result is further supported by the result of Figure 3.

As seen in Figure 3, students' responses are more centered around "Agree" and "Strongly Agree" for the Curriculum with an overall average response of more than $80 \%$. For the same heading, the overall response for "Agree" and 'Strongly Agree" varies from $69 \%$ to $96 \%$. Among the five questions, Q15 ("The learning ...learning outcomes") has the highest contribution towards developing positive perception regarding the Curriculum. About $96 \%$ of students positively agreed that the learning activities for the subject were relevant to the learning outcomes. This high level of agreement could have resulted from students' 
understanding of the constructive alignment between topic learning outcomes, subject learning outcomes and course learning outcomes. These outcomes were clearly communicated to the students and shown how all the activities (asynchronous, synchronous) are aligned with the learning outcomes and relevant to the course through various synchronous sessions. It is noteworthy that for the same area of course design, Q9 ("the workload demand ... remote online learning") has the least positive agreement rate (69\%) among the questions (Q9, Q15, and Q16). It is most likely that this rating could have resulted from the change in the mode of teaching. As a result of the COVID-19, all teachings were made online and remote with the change in assessment regime. Students were required to complete all assessments individually and need to come prepared for the synchronous learning. This change demanded extra effort from the students' side. Some students must have struggled to manage it and perceived all these things adding up to their workload. This result can further be corroborated with the result of Figure $\mathbf{3}$ (refer to Students' Perception) where it has been discussed that how change in the assessment regime resulted in the negative rating regarding online collaboration.

It is to note that because of the abrupt online transition, the present author did not have enough time to prepare lecturespecific video for online learning, instead video content from freely available online resources related to the lecture content was provided in the LMS. Students were asked in the survey about its relevance towards the course learning outcome (refer to Table 5, Q10). The calculated mean value of 4.06 (refer to Table 3) shows a very good agreement towards the relevance of video content towards fulfilling learning objective of the course. This high agreement is also evident from the result of Figure 3 . It is seen in Figure 3 that about $90 \%$ students responded positively to the question 10 . This result indicates that videos collated from freely available resources could be a good alternate to teach the student topic-specific knowledge in this crisis time when properly planned, topic-specific lecture videos are not possible to develop. The online learning with student access to content related videos has potential pedagogical benefits as these videos can be viewed and discussed outside the class time (Tiernan, 2015) and can also promote collaborative learning.

Though students have a positive perception towards the content of videos collated from other sources and provided as part of learning and teaching, they prefer to have content specific pre-recorded lecture videos by the lecturer. This is indicated by the lowest mean of 3.71 for Q17 ("I prefer ... videos) among two questions in Course Content area (refer to Table 3). The mean of 3.71 is significantly higher than the mean rating of 3, but when it compares with the mean of Q10, it is about $9 \%$ lower. The same result is also evident from Figure 3 which shows that about 77\% students expressing positive rating for Q17, whereas the rating for Q10 is $90 \%$. This result provides valuable feedback for ERL implementation as students prefer to have course specific videos developed by their lecturer. From the above discussion it can be argued that though collated materials could be a valuable resource for immediate use as part of the ERL but in a long run there is no substitute for content specific videos developed by the lecturer. This aspect needs to be carefully considered in designing content specific videos for future ERL implementation as it is still not clear when normalcy will return.

\section{Feedback}

Feedback is considered one of the powerful activities that enhance learning and engage students (Conrad \& Dabbagh, 2015). Feedback becomes paramount in online learning to overcome the hurdle of the communication between teacher and students. This is more important now than ever. Because of the COVID-19 lockdowns and closure of the educational institute, teachers do not have the luxury of physical cues, instead must transcend the virtual distance to address the concern of the students through an effective feedback and must establish the care of duty. To deliver effective feedback, present author relied on email communication and synchronous live in-class learning. To understand how students perceived the delivered feedback from the lecturer, students' opinions were collected through questions in two areas: Response time and Support. The result of the survey is presented in Figure $\mathbf{4}$ which shows strong agreement towards the survey questions by the students. The average agreement is about $85 \%$. 


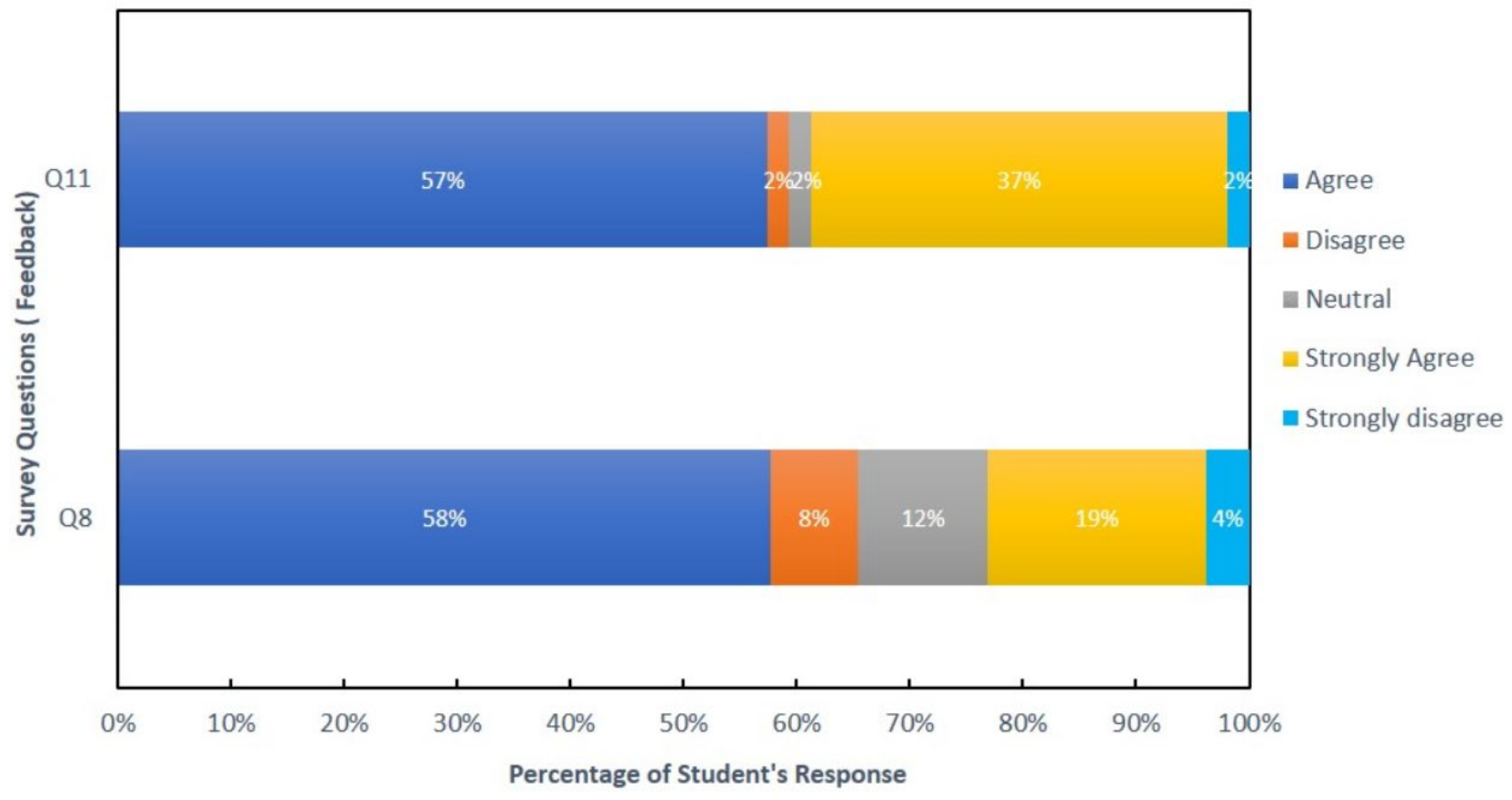

Figure 4. Survey result for the Heading- Feedback

Table 6. Descriptive Statistics for the Heading- Feedback

\begin{tabular}{cccc}
\hline Question Number & Description & Area & Mean (SD) \\
\hline Q8 & Response time from Lecturer is quicker in remote online teaching. & Response time & 3.81 (0.97) \\
\hline Q11 & The lecturer was supportive and responsive to my questions. & Support & 4.25 (0.77) \\
\hline
\end{tabular}

The descriptive statistics (refer to Table 6) for the Feedback further support the result of Figure 4. The overall mean for Feedback is 4.03 which is the highest mean among all means calculated for the headings (also refer to Table 3). The calculated mean is about $34 \%$ higher than the mean value of 3 . This clearly indicates that feedback provided by the lecturer was very effective in terms of the support and response. Past research has shown that the prompt communication and feedback by faculty promote online engagement and can compensates the physical distance associated with online learning (Tanis, 2020). It is very important that students should be responded in a timely fashion and with utmost priority. Unlike the normal situations where students had the opportunity to drop-by the lecture's office for any discussion and feedback, the medium available for such purpose during the crisis time is online communication. Any delay in the response can create anxiety and stress in students which could affect their mental wellbeing and learning. Therefore, response and support in this crisis time is of utmost importance. The above result clearly shows that these two aspects of ERL were successfully implemented in the author's course.

\section{Quality}

Quality is a multidimensional term, simultaneously dynamic and contextual, and its actual meaning in higher education is unclear (Dicker, Garcia, Kelly, \& Mulrooney, 2019). For the context of the present study, the quality of ERL is defined in terms of satisfaction associated with the fulfillment of the expectation that the student had regarding the remote online learning. To assess student's perception of the quality of ERL, students were asked to give their opinion on two areas of ERL: Expectation and Satisfaction. The survey result of the students' perception on quality of ERL is presented in Figure 5. 


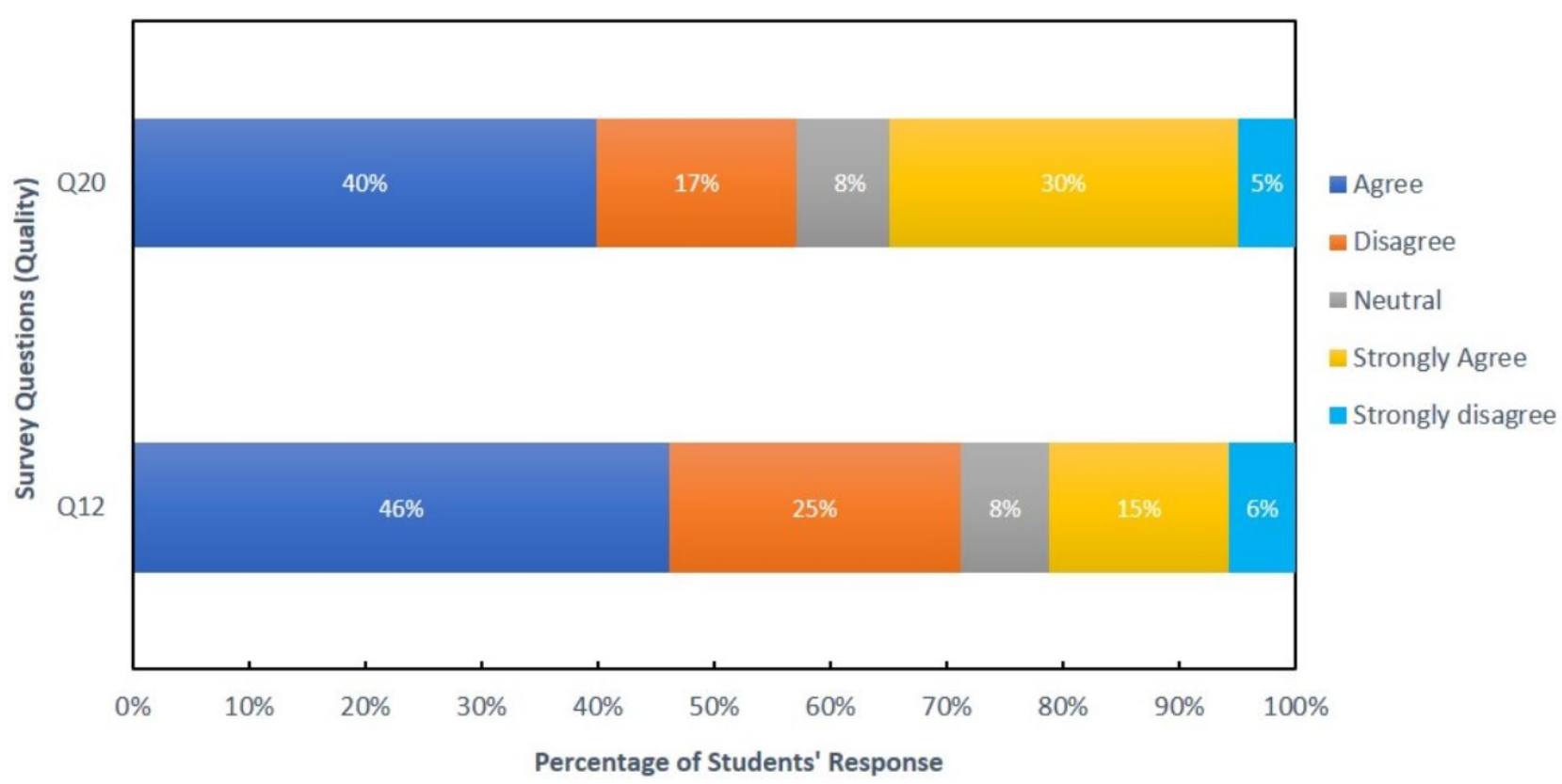

Figure 5. Survey result for the Heading- Quality

Table 7. Descriptive Statistics for the Heading- Quality

\begin{tabular}{cccc}
\hline Question Number & Description & Area & Mean (SD) \\
\hline Q12 & My expectations for the subject were met through remote online learning & Product quality & $3.4(1.19)$ \\
\hline Q20 & Overall, I am satisfied with remote online learning & Process quality & $3.6(1.24)$ \\
\hline
\end{tabular}

It is seen in Figure 5 that students' perception regarding the quality of ERL is marginal, though the calculated mean for the question items is above the neutral rating of 3 (refer to Table 7). A close analysis of Figure 5 result indicates that the marginalization of students' response towards the ERL quality is largely affected by the disagreement rate for Q12 ("My expectation ...remote online learning") which is $25 \%$. This disagreement rate is about $32 \%$ higher than for Q20 ("overall ... remote online learning") and have affected the student's perception in overall. Table 7 presents descriptive statics for Quality which further explains students' perception.

The result presented in Table 7 shows that for Q12, the calculated mean is 3.4, which is 6\% less than that for Q20. This low level of expectation towards the unit could be the result of a change in the assessment regime. Assessment techniques are one of the key issues in determining the effectiveness of the distance learning (Markova et al., 2017). This result can be linked to the result of the earlier section where the impact of the change in the assessment towards students' perception of online collaboration has been discussed (refer to Student's Perception). It is most likely that students did not expect to see any change in the assessment when courses are to be taught remotely and online but when changes occurred, it may have reflected as not fulfilling their original expectation regarding the quality of ERL and could have impacted their opinion. This needs further investigation in future research.

\section{Technology \& Resource}

Technology plays a major role in remote learning which indirectly influence the learning environment by reducing the learner's anxiety and offers students an access to countless resources. As a result of the COVID-19 pandemic, there occurred unprecedented transition to the online learning which posed various challenges including technical. To understand how students' have perceived this transition, they were asked to give their opinion on technological aspect of online transition and availability of teaching and learning materials in the online learning platform (college LMS) and library. The technological resources that were primarily used in the author's course were LMS (Canvas), online textbooks, Zoom-based video conferencing, online videos, and emails. In Australia, residential broadband internet connection is available through variety of transmission media such as ADSL (Asymmetric Digital Subscriber Line), cable, fiber, satellite and wireless. The average download speed of broadband connection in Australia is about $41.78 \mathrm{Mbps}$, which is considered good for online learning. Therefore, it is assumed that student should not have any issue in accessing resources online and participate in remote learning. Figure 6 presents the result of the survey that shows about $79 \%$ students hold positive perceptions towards the technological and resource aspects of ERL transition. 


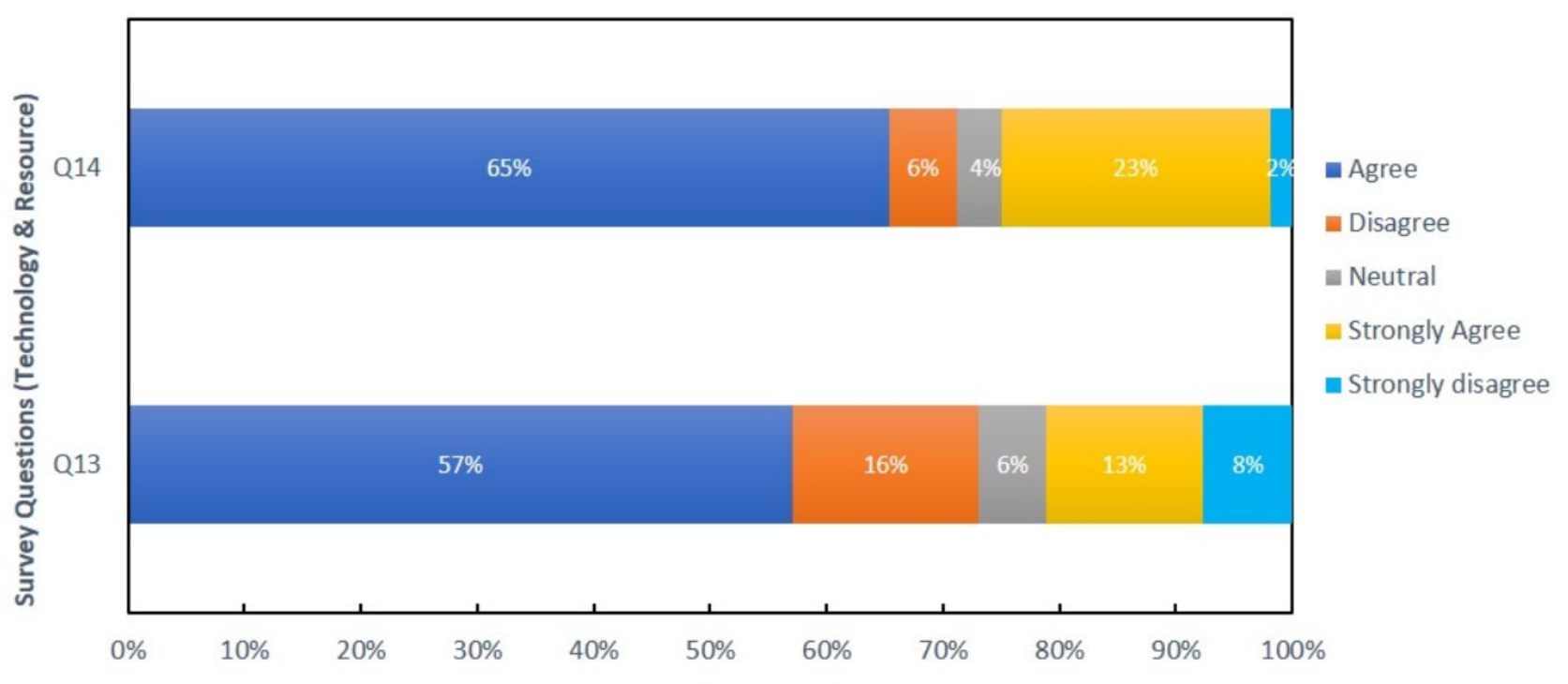

Percentage of Student's Response

Figure 6. Survey result for the heading -Technology \& Resource

Table 8. Descriptive Statistics for the Heading- Technology \& Resource

\begin{tabular}{cccc}
\hline Question Number & Description & Area & Mean (SD) \\
\hline Q13 & Transition from face-to-face Teaching to remote online teaching was smooth without & Technology & 3.5 (1.16) \\
\hline Q14 & Online learning resources are made easily available through library service and in Canvas. & Resource & 4.02 (0.83) \\
\hline
\end{tabular}

Further analysis of an individual question revealed that students hold more positive perceptions towards the availability of teaching and learning materials in the online learning platform (Q14) than technological aspect of online transition (Q13). The perception is about 20\% higher for Q14. This can be further confirmed by the calculated mean of 3.5 for Q13 (refer to Table 8). Unlike face-to-face teaching, remote online teaching relies heavily on technology. The knowledge, skill, and comfort in using online technology could have affected students' positive rating towards online transition. This needs further investigation. Nonetheless, on the basis of overall positive response (70\%) it can be argued that students had no major issue during the transition from face-to-face to the remote online class and the technology employed for this purpose was well received by the students. On the other hand, students were quite satisfied with the way teaching and learning materials were made available to them to access remotely as evident from the high mean value of 4.02 for Q14 (refer to Table 8). Based on these results, it can be argued that the need to create a learning environment where students can access learning related materials safely and reliably during the COVID19 pandemic was achieved through the successful use of technology and resources.

\section{CONCLUSION}

The present paper discussed the outcome of the survey which was primarily conducted to understand students' perception of crisis pedagogy of remote learning during the COVID-19 propelled closure of tertiary Institute. Eighty-one postgraduate students from the project management program at Asia Pacific International College, a private non-university higher education provider in Sydney, participated in the survey. The students expressed their opinion about ERL under five broad headings: student's perception, curriculum, feedback, quality, and technology \& resource. The result showed that students perceived ERL quite positively and are satisfied with overall learning experience. The highest satisfaction was observed for the feedback that students received from faculty followed by the technology \& resources that was employed during the ERL. The ERL model adopted in this study has two components: self-paced asynchronous learning and faculty-guided synchronous learning. The first goal of ERL was achieved through self-paced asynchronous learning where students accessed the learning and teaching materials safely, reliably, and remotely that were made available in the LMS. Similarly, the second goal of ERL was achieved through faculty-guided synchronous learning where students participated in interactive learning as in face-to-face through the live Zoom sessions.

The current study offers several implications for practice and research. First, there is a need for effective assessment design for ERL. Unlike face-to face teaching students do not have any other opportunity to collaborate and interact with peers in online learning other than collaborative work. Interaction and assessment techniques are keys in effective remote learning. In addition, collaborative work also helps students to manage their workload demand when assessments are done in collaboration rather than individually. Therefore, assessment for ERL should include the components of collaborative interactional learning. Through collaboration a sense of online community can also be developed which is very essential for ERL implementation.

Second, there is a need for developing content specific learning videos. There is no doubt that videos collated from various resources can be used to fulfill the immediate need, however they cannot be the substitute for the content specific learning videos 
developed by the course instructor. As the delivery of remote learning depends heavily on the technology, there is also a need to provide IT support for remote learning, especially for the technology that is going to be used so that students can have confidence about their own ability to use IT for remote learning. Fourth, there is a need to understand students' preference between two components of the ERL, i.e., self-paced asynchronous learning and faculty-guided synchronous learning. Such comparison enables educational institute to adjust their curriculum to suit students' interest and to enhance overall remote learning experience.

Finally, to assess the implication of the ERL model adopted in this study from a broader perspective, a similar study with a larger sample size with probabilistic sampling is recommended. During online remote learning neither the educational institute nor the student have control over the internet speed which they use to access their online course. Understanding how internet speed influences student perceptions of their experience in ERL is of great valuable as it enables institute to make adjustment in their online course to improve the student learning experience.

It is noteworthy that the ERL implementation is contextual as learner's requirements and contextual needs may differ. Therefore, students' perceptions and feedback are critical in improving the on-going remote teaching practice and also to be prepared for any such crisis events that may occur in the future. It is unknown how long ERL will continue or what kind of other situations we may face in the future, so educational institutions and students alike must be better prepared for any such eventuality. The knowledge and experience that was gained in dealing with the crisis through ERL as discussed in the present paper could be a valuable aid.

Author contributions: All authors have sufficiently contributed to the study, and agreed with the results and conclusions.

Funding: No funding source is reported for this study.

Declaration of interest: No conflict of interest is declared by authors.

\section{REFERENCES}

Andrews, D., Nonnecke, B., \& Preece, J. (2003). Electronic survey methodology: A case study in reaching hard to involve Internet Users. International Journal of Human-Computer Interaction (Vol. 16). https://doi.org/10.1207/S15327590IJHC1602_04

Australian Trade and Investment Commiss, \& Ion. (n.d.). Facts about studying in Australia. Retrieved on 27 January 2021 from https://www.studyinaustralia.gov.au/English/Why-Australia/facts-about-studying-in-australia

Australian Trade and Investment Commission. (n.d.). International student data. Retrieved on 27 January 2021 from https://internationaleducation.gov.au/research/international-student-data/Pages/default.aspx

Bozkurt, A, Jung, I., Xiao, J., Vladimirschi, V., Schuwer, R., Egorov, G., ... Paskevicius, M. (2020). A global outlook to the interruption of education due to COVID-19 Pandemic: Navigating in a time of uncertainty and crisis. Asian Journal of Distance Education, 15(1), 1-126. https://doi.org/10.5281/zenodo.3878572

Bozkurt, A., \& Sharma, R. C. (2020). Emergency remote teaching in a time of global crisis due to CoronaVirus pandemic. Asian Journal of Distance Education, 15(1), 2020. Retrieved from https://www.asianjde.org/ojs/index.php/AsianJDE/article/view/447

Cole, M. S., Feild, H. S., \& Harris, S. G. (2017). Student Learning Motivation and Psychological Hardiness: Interactive Effects on Students' Reactions to a Management Class. Academy of Management Learning \& Education, 3(1). Retrieved from http://citeseerx.ist.psu.edu/viewdoc/download?doi=10.1.1.475.1002\&rep=rep1\&type=pdf

Conrad, S. S., \& Dabbagh, N. (2015). Examining the Factors that Influence how Instructors Provide Feedback in Online Learning Environments. International Journal of Online Pedagogy and Course Design, 5(4), 47-66. https://doi.org/10.4018/ijopcd.2015100104

Dicker, R., Garcia, M., Kelly, A., \& Mulrooney, H. (2019). What does 'quality' in higher education mean? Perceptions of staff, students and employers. Studies in Higher Education, 44(8), 1425-1441. https://doi.org/10.1080/03075079.2018.1445987

Dumas, D. (2018). Understanding High School Students' Perceptions of Their Learning Opportunities: A Doubly Latent Approach. Frontiers in Education, 3, 76. https://doi.org/10.3389/feduc.2018.00076

El-Mowafy, A., Kuhn, M., \& Snow, T. (2013). Blended learning in higher education: Current and future challenges in surveying education. Issues in Educational Research, 23(2), 132-150. Retrieved from http://www.iier.org.au/iier23/el-mowafy.pdf

Eom, S. B., \& Ashill, N. (2016). The Determinants of Students' Perceived Learning Outcomes and Satisfaction in University Online Education: An Update*. Decision Sciences Journal of Innovative Education, 14(2), 185-215. https://doi.org/10.1111/dsji.12097

Gamage, K. A. A., de Silva, E. K., \& Gunawardhana, N. (2020). Online delivery and assessment during COVID-19: Safeguarding academic integrity. Education Sciences, 10(11), 1-24. https://doi.org/10.3390/educsci10110301

Hodges, C., Moore, S., Lockee, B., Trust, T., \& Bond, A. (2020). The Difference Between Emergency Remote Teaching and Online Learning. Retrieved from https://er.educause.edu/articles/2020/3/the-difference-between-emergency-remote-teaching-andonline-learning

Jankowski, N. A. J. (2020). Assessment during a crisis: Responding to a global pandemic. Urbana, IL: University of Illinois and Indiana University, National Institute for Learning Outcomes Assessment. https://www.learningoutcomesassessment.org/wpcontent/uploads/2020/08/2020-COVID-Survey.pdf 
Khanal, R. (2020). An Investigation of the Effectiveness of Flipped classroom teaching in project management course: A cas study of Australian Higher Education. PUPIL: International Journal of Teaching, Education and Learning, 4(2), $348-368$. https://doi.org/10.20319/pijtel.2020.42.348368

Markova, T., Glazkova, I., \& Zaborova, E. (2017). Quality Issues of Online Distance Learning. Procedia - Social and Behavioral Sciences, 237(June 2016), 685-691. https://doi.org/10.1016/j.sbspro.2017.02.043

McKimm, J., \& Barrow, M. (2009, September 27). Curriculum and course design. British Journal of Hospital Medicine. MA Healthcare Ltd. https://doi.org/10.12968/hmed.2009.70.12.45510

Means, B., \& Neisler, J. (2020). Suddenly Online: A National Survey of Undergraduates During the COVID-19 Pandemic. https://doi.org/10.51388/20.500.12265/98

Mohmmed, A. O., Khidhir, B. A., Nazeer, A., \& Vijayan, V. J. (2020). Emergency remote teaching during Coronavirus pandemic: the current trend and future directive at Middle East College Oman. Innovative Infrastructure Solutions, 5(3), 1-11. https://doi.org/10.1007/s41062-020-00326-7

Mora, H., Signes-Pont, M. T., Fuster-Guilló, A., \& Pertegal-Felices, M. L. (2020). A collaborative working model for enhancing the learning process of science \& engineering students. Computers in Human Behavior, 103, $140-150$. https://doi.org/10.1016/j.chb.2019.09.008

Morgan, D. L. (2015). From themes to hypotheses: Following up with quantitative methods. Qualitative Health Research, 25(6), 789793. https://doi.org/10.1177/1049732315580110

Naik, G. L., Deshpande, M., Shivananda, D. C., Ajey, C. P., \& Patel, G. C. M. (2021). Online Teaching and Learning of Higher Education in India during COVID-19 Emergency Lockdown. Pedagogical Research, 6(1), em0090. https://doi.org/10.29333/pr/9665

Nam-Nguyen, V., Truong, T. T. A., Ly, D. T. T., \& Dagamac, N. H. A. (2020). Perceptions of Environmental Science and Management Students on Synchronous Online Teaching of Environmental Policies: Learning Experience from Southeast Asian Cohort. Pedagogical Research, 6(1), em0084. https://doi.org/10.29333/pr/9287

Pace, C., Pettit, S., \& Barker, K. (2020). Best Practices in Middle Level Quaranteaching: Strategies, Tips and Resources Amidst COVID-19. Becoming: Journal of the Georgia Middle School Association, 31(1), 1-13. https://doi.org/10.20429/becoming.2020.310102

Pal, D., \& Vanijja, V. (2020). Perceived usability evaluation of Microsoft Teams as an online learning platform during COVID-19 using system usability scale and technology acceptance model in India. Children and Youth Services Review, 119, 105535. https://doi.org/10.1016/J.CHILDYOUTH.2020.105535

Pattanaphanchai, J. (2019). An investigation of students' learning achievement and perception using flipped classroom in an introductory programming course: A case study of Thailand higher education. Journal of University Teaching and Learning Practice, 16(5), Article 4. https://ro.uow.edu.au/jutlp/vol16/iss5/4

Rahiem, M. D. H. (2020). The Emergency Remote Learning Experience of University Students in Indonesia amidst the COVID-19 Crisis. International Journal of Learning, Teaching and Educational Research, 19(6), 1-26. https://doi.org/10.26803/ijlter.19.6.1

Schleyer, T. K. L., \& Forrest, J. L. (2000). Methods for the design and administration of web-based surveys. Journal of the American Medical Informatics Association, 7(4), 416-425. https://doi.org/10.1136/jamia.2000.0070416

Sunasee, R. (2020). Challenges of Teaching Organic Chemistry during COVID-19 Pandemic at a Primarily Undergraduate Institution. Journal of Chemical Education, 0-5. https://doi.org/10.1021/acs.jchemed.0c00542

Taber, K. S. (2018). The Use of Cronbach's Alpha When Developing and Reporting Research Instruments in Science Education. Research in Science Education, 48(6), 1273-1296. https://doi.org/10.1007/s11165-016-9602-2

Tanis, C. J. (2020). The seven principles of online learning: Feedback from faculty and alumni on its importance for teaching and learning. Research in Learning Technology, 28(1063519), 1-25. https://doi.org/10.25304/rlt.v28.2319

Tehan, D. (2019). International education makes significant economic contribution [Media release]. Ministers' Media Center, Department of Education, Skills and Employment. Retrieved from https://ministers.dese.gov.au/tehan/internationaleducation-makes-significant-economic-contribution

Teräs, M., Suoranta, J., Teräs, H., \& Curcher, M. (2020). Post-Covid-19 Education and Education Technology 'Solutionism': A Seller's Market. Postdigital Science and Education, 2(1), 863-878. https://doi.org/10.1007/s42438-020-00164-X

Tiernan, P. (2015). An inquiry into the current and future uses of digital video in University teaching. Education and Information Technologies, 20(1), 75-90. https://doi.org/10.1007/s10639-013-9266-8

UNESCO. (2020). UN Secretary-General warns of education catastrophe, pointing to UNESCO estimate of 24 million learners at risk of dropping out. Retrieved from https://en.unesco.org/news/secretary-general-warns-education-catastrophe-pointing-unescoestimate-24-million-learners-0

Universities Autralia. (2020). COVID-19 to cost universities $\$ 16$ billion by 2023 . Retrieved from https://www.universitiesaustralia.edu.au/media-item/covid-19-to-cost-universities-16-billion-by-2023

World Bank. (2020). The COVID-19 Pandemic. https://doi.org/10.1596/33696

Yang, Y., Yang, Y., \& Durrington, V. (2010). Investigation of Students' Perceptions of Online Course Quality. International Journal on E-Learning, 9(3), 341-361. https://www.learntechlib.org/primary/p/29460/ 
Zawacki-Richter, O., Conrad, D., Bozkurt, A., Aydin, C., Bedenlier, S., Jung, I., ... Xiao, F. (2020). Elements of Open Education: An Invitation to Future Research. International Review of Research in Open and Distance Learning, 21, 319-334. https://doi.org/10.19173/irrodl.v21i3.4659 